Check for updates

Cite this: Mater. Adv., 2021, 2, 7077

Received 9th July 2021, Accepted 22nd September 2021

DOI: 10.1039/d1ma00595b

rsc.li/materials-advances

\section{Hybrid covalent adaptable networks from cross-reactive poly( $\varepsilon$-caprolactone) and poly(ethylene oxide) stars towards advanced shape-memory materials $\dagger$}

\begin{abstract}
Jérémie Caprasse, Raphaël Riva, Jean-Michel Thomassin and Christine Jérôme (D) *
The synthesis and properties of hybrid poly( $\varepsilon$-caprolactone) ( $P C L$ )-poly(ethylene oxide) ( $P E O)$ covalent adaptable networks have been investigated. This novel material uniquely combines recycling and reconfiguration capabilities with temperature and water-triggered shape-memory properties. Firstly, 4-arm star-shaped PEO and PCL were end-capped with furan and maleimide moieties, respectively. Then, equimolar mixtures of these cross-reactive stars were melt-blended and cured leading to PCL-PEO hybrid networks by Diels-Alder addition between chain-ends. The PCL/PEO content of the networks was varied by using PCL stars of different molar masses allowing tailoring the material hydrophilicity. We evidenced that the as-obtained hybrid networks exhibit not only excellent temperature-triggered shape-memory properties (high fixity and high and rapid recovery) but also valuable water-triggered shape-memory properties characterized by a high fixity and a recovery-rate controlled by the network composition. Remarkably, thanks to the introduction of thermo-reversible Diels-Alder adducts within the covalent network, we demonstrated that this material can be easily recycled while preserving the shape-memory performances. Therefore, the reconfiguration of the so-called permanent shape is straightforward making this material a potential candidate for applications in water responsive medical devices. The hydrolytic stability of these networks was demonstrated over a period of one month of immersion in water at physiological $\mathrm{pH}$.
\end{abstract}

\section{Introduction}

Shape-memory polymers (SMPs) are a class of stimuliresponsive materials that can be elastically deformed and then fixed into a temporary shape by immobilization of the network chains. They later recover to their original (also called permanent) shape when exposed to an external stimulus that gives back their mobility to the network chains. The formation of threedimensional covalent networks by chemical crosslinking of the polymer chains enhances the thermal stability and the structural integrity of the materials leading to an improvement of the mechanical properties, typically a significant increase of the

Center for Education and Research on Macromolecules, CESAM RU,

University of Liège, B6a Sart-Tilman, B-4000 Liège, Belgium.

E-mail: c.jerome@uliege.be

$\dagger$ Electronic supplementary information (ESI) available: The detailed synthesis of the functional stars and precursors (PCL-4COOH, PCL-4MAL, PCL-4OH, PEO4FUR), tables of shape-memory before and after ageing in water. H-NMR and SEC of PEO-4FUR, Raman spectra of the stars and CANs, DSC curves of 70:30 CAN before and after recycling, stress-strain curves of CANs, illustration of recycling and the shape memory of recycled materials are provided. See DOI: 10.1039/ d1ma00595b elastic behaviour in response to strain deformations. Moreover, chemically cross-linked SMPs exhibit most often better performances as compared to physical networks. ${ }^{1}$ Nevertheless, these covalent networks suffer from the severe drawback to prevent recycling or reconfiguration in contrast to thermoplastics. The creation of covalent but reversible bonds between polymer chains was thus developed to overcome this limitation. In 2010, C. Kloxin and C. Bowman defined this family of materials that include reversible covalent bonds as covalent adaptable networks (CANs). ${ }^{2}$ Inserting reversible binding groups in shape-memory covalent networks has thus emerged as a successful strategy for imparting them recyclability, and also generating additional functionality such as self-healing properties $^{3}$ or reconfiguration ability. ${ }^{4}$ In that context, Defize et al. reported on the preparation of $\operatorname{poly}(\varepsilon-$ caprolactone) (PCL) CANs based on the integration of furan-maleimide Diels-Alder adducts in the network. ${ }^{5-7}$ These CANs not only exhibit excellent shape-memory properties, i.e. high fixity and temperature-triggered recovery but thanks to the thermo-reversible character of this DielsAlder reaction, they are also fully recyclable at high temperature where the cleavage of the furan-maleimide adducts occurs. 
PCL being a biocompatible and bioresorbable material, it is attractive for application in the medical field. Therefore, advanced PCL-based SM materials are developing to tackle various biomedical needs such as smart implants ${ }^{8,9}$ or scaffolds. $^{10}$

Besides, dual responsive SM materials exhibiting a response to an electric, ${ }^{11,12}$ magnetic, ${ }^{13}$ photo- ${ }^{14}$ or chemical ${ }^{15}$ trigger in addition to the temperature are also particularly attractive. When biomedical applications are envisioned, water responsive SMPs, that recover their shape by immersing the sample in water at constant body temperature, are particularly appealing. ${ }^{16-19}$ To impart such water sensitivity to polyesters based SMPs, they have been combined notably with poly(ethylene oxide) (PEO), a highly hydrophilic and bioeliminable component. PCL and PEO were combined in multiblock polyurethanes leading to water-triggered SM thermoplastics. ${ }^{20,21}$ As far as covalent networks are concerned, the synthesis of polyesters (PLA, PLGA, PCL) and PEO double interpenetrated networks (IPNs) was reported ${ }^{22,23}$ evidencing potential of these fully bioresorbable materials as waterinduced shape-memory materials. Nevertheless, these IPNs combining two interpenetrated covalent networks without reversible bond cannot be recycled, reprocessed nor reconfigured.

Herein, we investigated for the first time the PCL and PEO combination in a single covalent adaptable network to provide novel recyclable and reconfigurable water-triggered shape-memory materials. The mechanical so as the temperature and water-triggered shape-memory properties were evaluated in function of the PCL/PEO content of the networks and their recyclability was demonstrated. This hybrid PEO-PCL covalent network was obtained by mixing 4-arm star-shaped PEO and PCL bearing furan and maleimide endgroups, respectively. The formation of the Diels-Alder adducts allowed the intimate network formation between both types of cross-reactive stars (Scheme 1). The thermo-reversibility of these adducts allowed reprocessing and recyclability of the material while preserving the water-triggered shape-memory performances.

\section{Experimental section}

\section{Materials}

Toluene, dichloromethane $\left(\mathrm{CH}_{2} \mathrm{Cl}_{2}\right)$, diethyl ether, chloroform and methanol, from Chem-Lab, as well as $N, N$-dimethylformamide (DMF), succinic anhydride, triethylamine $\left(\mathrm{NEt}_{3}\right)$, dicyclohexylcarbodiimide (DCC), 4-dimethylamino-pyridine (DMAP), dibutyltin dilaurate and 2-(isocyanatomethyl)-furan from Aldrich were used as received. 4-Arm star-shaped PCL bearing hydroxyl groups at the end of each $\operatorname{arm}\left(M_{\mathrm{n}}=8000 \mathrm{~g} \mathrm{~mol}^{-1}\right.$, PCL-4OH) were kindly provided by Perstop-caprolactones. PCL$4 \mathrm{OH}$ of lower molar mass $\left(M_{\mathrm{n}}=4000 \mathrm{~g} \mathrm{~mol}^{-1}\right)$ was synthesized following a procedure adapted from literature ${ }^{5,6}$ (see ESI $\dagger$ ). The 4-arms star-shaped PEO bearing hydroxyl groups as chain-ends $\left(M_{\mathrm{n}}=10000 \mathrm{~g} \mathrm{~mol}^{-1}, \mathrm{PEO}-4 \mathrm{OH}\right)$ was supplied by CreativePEGWorks.

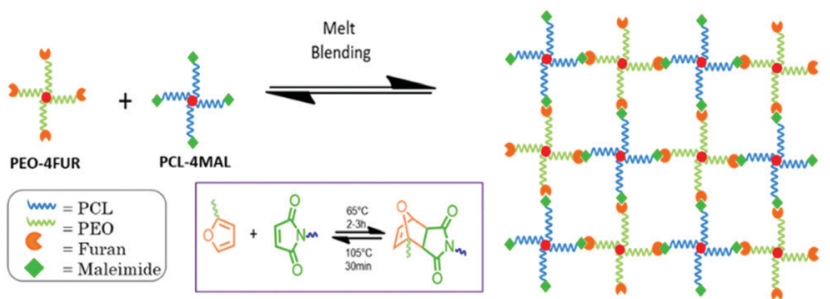

Scheme 1 Strategy for the synthesis of the PCL-PEO hybrid covalent adaptable network by introduction of thermo-reversible Diels-Alder adducts.

\section{Synthesis of 4-arm star-shaped maleimide end-capped PCL (PCL-4MAL)}

The conversion of the hydroxyl end-groups of PCL-4OH in maleimide moieties to get PCL-4MAL is a well optimized and already reported process. ${ }^{6,7}$ It was applied to PCL-4OH of two molar masses, 8000 and $4000 \mathrm{~g} \mathrm{~mol}^{-1}$ (see ESI $\dagger$ ) with a conversion equal to $85 \%$ in both cases leading to the PCL4MAL8k ( $D$ 1.21) and PCL-4MAL4k ( $D$ 1.23), respectively.

\section{Synthesis of 4-arm star-shaped furan end-capped PEO (PEO-4FUR)}

The chain-ends functionalization of the PEO-4FUR was achieved by the reaction between the hydroxy groups of PEO$4 \mathrm{OH}$ stars with furfuryl isocyanate as shown on Scheme S1 (ESI $\dagger)$. For that purpose, $10 \mathrm{~g}$ of $\mathrm{PEO}-4 \mathrm{OH}(4.0 \mathrm{mmol}$ in hydroxyl group) were transferred into a previously dried round bottom glass flask and three azeotropic distillations with anhydrous toluene, were performed. Then, $100 \mathrm{~mL}$ of anhydrous $\mathrm{CH}_{2} \mathrm{Cl}_{2}$ was added in the flask. After the complete dissolution of the PEO, $0.471 \mathrm{~mL}(4.4 \mathrm{mmol})$ of furfuryl isocyanate and $0.01 \mathrm{~mL}$ (0.4 $\mathrm{mol} \%)$ of dibutyltin dilaurate were transferred into the reactive medium. After $24 \mathrm{~h}$ of stirring at $40{ }^{\circ} \mathrm{C}$, the reaction was stopped and the PEO-4FUR is recovered by precipitation in diethyl ether. PEO-4FUR was finally purified by dialysis $(\mathrm{MWCO}=1 \mathrm{kDa})$ against water during $12 \mathrm{~h}$ to remove the tin catalyst and recovered after freeze-drying. A white powder (8.5 g) is recovered (PEO-4FUR). A quantitative functionalization was determined by ${ }^{1} \mathrm{H}$ NMR analysis (Fig. S1, ESI $\dagger$ ). The SEC chromatogram (Fig. S2, ESI $\dagger$ ) showed a slight shift to lower elution volume of the peak apex demonstrating that the functionalization occurred properly.

${ }^{1} \mathrm{H}$ NMR $\left(\mathrm{CDCl}_{3}, \delta\right): 7.35$ (d, 4H, H furan); $6.31(\mathrm{~d}, 4 \mathrm{H}, \mathrm{H}$ furan); 6.22 (d, 4H, H furan); 4.31 (d, 8H, $-\mathrm{C}(\mathrm{O})-\mathrm{N}(\mathrm{H})-\mathrm{CH}_{2}-\mathrm{Fur}$ ); $4.2\left(\mathrm{t}, 8 \mathrm{H},-\mathrm{CH}_{2}-\mathrm{O}-\mathrm{C}(\mathrm{O})-\mathrm{N}(\mathrm{H})-\right), 3.62$ (m, 1060H, H PEO). Conversion of the chain-ends in furan moiety $>99 \%$.

\section{Preparation of the PEO-PCL hybrid networks}

Hybrid networks are formed by mixing PEO-4FUR and PCL-4MAL stars in an extruder at $90{ }^{\circ} \mathrm{C}$ in equimolar amounts of reactive functions, followed by a thermal post-curing in a mould. Two types of networks have been prepared based on the same PEO-4FUR $10400 \mathrm{~g} \mathrm{~mol}^{-1}$ mixed with the PCL-4MAL $9700 \mathrm{~g} \mathrm{~mol}^{-1}$ (51:49 network, these numbers represent the 
mass proportion of each polymer in the blend) or with PCL-4MAL $4000 \mathrm{~g} \mathrm{~mol}^{-1}$ (70:30 network). More precisely, for the first network, $2.3 \mathrm{~g}$ of PEO-4FUR and $2.2 \mathrm{~g}$ of PCL-4MAL8k stars were grinded together and injected in a $6 \mathrm{~cm}^{3}$ co-rotating twin screw mini-extruder (Xplore, DSM). They were meltblended at $90{ }^{\circ} \mathrm{C}$ during $45 \mathrm{~min}$ at $150 \mathrm{rpm}$. The blend was collected in a $0.5 \mathrm{~mm}$ thick mould and processed by compression moulding at $100{ }^{\circ} \mathrm{C}$ and 75 bars during $1 \mathrm{~h}$ in order to obtain a flat sheet shape of material. It was followed by a postcuring of $72 \mathrm{~h}$ at $65{ }^{\circ} \mathrm{C}$ to obtain a fully crosslinked material.

The same procedure is followed to synthesize the second network, except for stars quantities. In this blend, $3 \mathrm{~g}$ of PEO4FUR $10400 \mathrm{~g} \mathrm{~mol}^{-1}$ and $1.4 \mathrm{~g}$ of PCL-4MAL $8800 \mathrm{~g} \mathrm{~mol}^{-1}$ were used to achieve the equimolar ratio of reactive functions.

\section{Swelling experiment}

Samples $(0.5 \mathrm{~cm} \times 0.5 \mathrm{~cm} \times 0.5 \mathrm{~mm})$ were immersed in chloroform for $48 \mathrm{~h}$ at room temperature in order to reach swelling equilibrium. The resulting gels were collected carefully and weighted in order to determine the amount of solvent absorb by the crosslinked materials. Then, they were dried under vacuum until constant weight in order to determine the insoluble fraction. The swelling ratio and the insoluble fraction were calculated according to the following equations. area under the PEO peak at $842 \mathrm{~cm}^{-1}$ and analysed thanks to the program OriginPro2016.

Differential scanning calorimetry (DSC) was performed on a DSC Q100 (TA Instruments) calibrated with indium. For the dry material, a sample is transferred in the DSC oven at $20{ }^{\circ} \mathrm{C}$ and a cooling ramp of $10{ }^{\circ} \mathrm{C} \min ^{-1}$ is applied until $-80{ }^{\circ} \mathrm{C}$. After 5 min of temperature stabilization, a heating ramp of $10{ }^{\circ} \mathrm{C} \min ^{-1}$ is applied until $100{ }^{\circ} \mathrm{C}$. This cooling-heating cycle is repeated for each sample, the melting temperature $\left(T_{\mathrm{m}}\right)$ and the enthalpy $\left(\Delta H_{\mathrm{m}}\right)$ being recorded during the second heating ramp. In case of water-swollen materials, the sample is transferred in the DSC oven at $20{ }^{\circ} \mathrm{C}$ and a cooling ramp of $10{ }^{\circ} \mathrm{C} \min ^{-1}$ is applied until $5{ }^{\circ} \mathrm{C}$. After $5 \mathrm{~min}$ of temperature stabilization, a heating ramp of $10{ }^{\circ} \mathrm{C} \mathrm{min}^{-1}$ is applied until $80{ }^{\circ} \mathrm{C}$.

Temperature shape-memory properties (fixity and recovery) were determined with a DMA Q800 (TA Instruments) using the tensile film clamp in controlled force mode. The sample $(2.5 \mathrm{~cm} \times 5 \mathrm{~mm} \times 0.5 \mathrm{~mm})$ is introduced and then heated at $65{ }^{\circ} \mathrm{C}$. After $5 \mathrm{~min}$ of temperature stabilization, an elongation stress ramp of $0.06 \mathrm{MPa} \min ^{-1}$ is applied to reach 0.6 MPa. The sample is cooled down under stress to $0{ }^{\circ} \mathrm{C}$ at $3{ }^{\circ} \mathrm{C} \mathrm{min}^{-1}$ and the temperature is maintained for $5 \mathrm{~min}$. Then, the stress is released and the fixity is determined at this stage by applying

$$
\text { Swelling ratio }=\frac{\text { weight of the swollen material }- \text { weight of the dried material }}{\text { weight of the dried material }} \times 100
$$

$$
\begin{aligned}
\text { Insoluble fraction }= & \frac{\text { weight of the dried material after swelling }}{\text { weight of the initial material }} \\
& \times 100
\end{aligned}
$$

Water swelling ratios were also measured by similar swelling experiments using water instead of chloroform.

\section{Characterization techniques}

Proton nuclear magnetic resonance $\left({ }^{1} \mathrm{H}\right.$ NMR) spectra were carried out by a Bruker Avance 400 apparatus at $25{ }^{\circ} \mathrm{C}$ at $400 \mathrm{MHz}$ in the Fourier-transform (FT) mode and using $\mathrm{CDCl}_{3}$ as solvent.

Size exclusion chromatography (SEC) analysis were recorded in $\mathrm{THF}$ at $45{ }^{\circ} \mathrm{C}$ with a flow of $1 \mathrm{~mL} \min ^{-1}$ on a Viscotek 305 TDA liquid chromatograph equipped with 2 PSS SDV linear M columns calibrated with polystyrene standards.

Raman spectra were recorded at room temperature using a Horiba-Jobin-Yvon Labram 300 confocal spectrometer provided with an Olympus BX40 microscope. The $647.1 \mathrm{~nm}$ line of a Spectra Physics model 168 Krypton ion laser was focused on a rectangular-shaped solid sample with an Olympus $50 \times(\mathrm{NA} 0.5$ ) objective. The laser power at the sample level was of the order of $25 \mathrm{~mW}$. Every spectrum was accumulated 6 times for 60 seconds. The detector is an Andor iDus BR-DD 401 CCD. All spectra were scaled up and, if necessary, baseline corrected with homemade software. All spectra were normalized by the the eqn (1). Finally, still in absence of stress, the sample is heated to $65{ }^{\circ} \mathrm{C}$ and the recovery is determined from the eqn (2). This cycle is repeated four times.

The fixity ratio:

$$
R_{\mathrm{f}}=\frac{\text { strain after stress release at } 0{ }^{\circ} \mathrm{C}}{\text { strain before stress release at } 0{ }^{\circ} \mathrm{C}} \times 100
$$

The recovery ratio:

$$
R_{\mathrm{r}}=\frac{\text { Strain at } 65^{\circ} \mathrm{C} \text { without stress for cycle } N \text { at } 0{ }^{\circ} \mathrm{C}}{\text { Strain at } 65^{\circ} \mathrm{C} \text { without stress for cycle }(N-1)} \times 100
$$

Water shape-memory properties were determined by immersing a flat strip $(2.5 \mathrm{~cm} \times 0.5 \mathrm{~cm} \times 0.5 \mathrm{~mm})$ in water for $1 \mathrm{~h}$. The dimension of the water swollen strip is then measured, especially the distance between the strip ends (initial hydrated shape). A stress is applied to bend the hydrated strip into a ring, the latter being dried at room temperature for $24 \mathrm{~h}$ under stress. After drying, the stress is released to reach the curved temporary shape. The fixity is calculated by measuring the distance between the two ends of the bended strip before and after stress release. To determine the recovery, the curved sample is immersed in water for $30 \mathrm{~min}$, the distance between the two strip ends is measured and compared to the initial hydrated shape.

Tensile properties were performed with an Instron 5586 machine linked to the BlueHill software on dried and hydrated samples $(2.5 \mathrm{~cm} \times 0.5 \mathrm{~cm} \times 0.5 \mathrm{~mm})$ at room temperature at 
a rate of $10 \mathrm{~mm} \min ^{-1}$. The modulus was determined by measuring the slope at the beginning of the curve.

\section{Local network reconfiguration}

A strip of the cross-linked material is bended by application of a stress and heated locally along the folding line at $120{ }^{\circ} \mathrm{C}$ during 30 min by contact with a heated metal. The bended sample is then let cooled down to room temperature. Checking the success of the network reconfiguration along that line is confirmed by heating the full sample to $65{ }^{\circ} \mathrm{C}$. This process is repeated two times at different spots of the strip to get the origami shaped more complex structure.

\section{Material recycling}

Two processes allow the recycling of the materials. Method A consists in cutting the network into small pieces and injecting them into a mini extruder at $120{ }^{\circ} \mathrm{C}$ for $2 \mathrm{~h}$. Then, the viscous mixture is collected and pressed at $65{ }^{\circ} \mathrm{C}$ during $30 \mathrm{~min}$. Finally, a post-curing of $48 \mathrm{~h}$ is performed at $65{ }^{\circ} \mathrm{C}$. In method $\mathrm{B}$, the sample is cut into small pieces which are placed into a mould, pressed at $130{ }^{\circ} \mathrm{C}$ under a pressure of 75 bars, for $1 \mathrm{~h}$ and then cured for $72 \mathrm{~h}$ at $60{ }^{\circ} \mathrm{C}$.

\section{Hydrolytic stability test}

The sample $(2.5 \mathrm{~cm} \times 0.5 \mathrm{~cm} \times 0.5 \mathrm{~mm})$ is immersed in $30 \mathrm{~mL}$ of phosphate buffer at $\mathrm{pH}=7.2$ and kept at room temperature for two weeks or one month. Then, the material is dried during $24 \mathrm{~h}$ and analysed by DMA and swelling to evidence any degradation of network.

\section{Results and discussion}

\section{Networks synthesis and characterization}

1.1 Network synthesis. As presented in Scheme 1, we aim to prepare a thermo-reversible covalent PEO-PCL hybrid network by the formation of Diels-Alder adducts between 4-arm star-shaped PEO end-capped with furan with 4-arm star-shaped PCL end-capped with maleimide (see $\mathrm{ESI} \dagger$ for synthesis and characterization of both precursors).

Typically, PEO-4FUR $\left(M_{\mathrm{n}}=10000 \mathrm{~g} \mathrm{~mol}^{-1}\right)$ was mixed with the PCL-4MAL8k or PCL-4MAL4k in a proportion respecting a 1:1 stoichiometric amount between furan and maleimide moieties, i.e. a PEO/PCL weight ratio of $51: 49$ and $70: 30$ is reached when the PEO-4FUR is blended with PCL-4MAL8k or PCL-4MAL4k, respectively. Knowing that PEO and PCL are non-miscible polymers, ${ }^{24-26}$ the two polymer precursors were firstly grinded at room temperature together to intimately mix both powders before introducing them into the extruder. It is also important to mention that the temperature of the extruder is crucial to observe a homogeneous blend and the network formation. Indeed, if the blending temperature is too high (above $90{ }^{\circ} \mathrm{C}$ ), the recovered blend is inhomogeneous and the network is not formed as evidenced by the important swelling and dissolution of the sample during the swelling test in chloroform, a good solvent for both PEO and PCL stars. Indeed, after extrusion at $105{ }^{\circ} \mathrm{C}$, only a few Diels-Alder adducts are formed, the retro-Diels-Alder reaction dominating at high temperature. $^{27-29}$ Thus, a very limited coupling reactions between PCL and PEO stars occurs, the blend is loosely crosslinked so that it highly swells and dissolves in chloroform and cannot be recovered. The inhomogeneity of the mixture after blending at $105{ }^{\circ} \mathrm{C}$ was evidenced by Raman spectroscopy microscope. About 15 different areas of the sample extruded at $105{ }^{\circ} \mathrm{C}$ were analysed by focalizing the laser on a $2 \mu \mathrm{m}$ diameter spot and recording the Raman spectrum for each place. Depending on the spot location, an important variation of the Raman intensity ratio between the characteristic peaks of PEO and PCL are observed. Normalizing all the 15 spectra on the peak at $842 \mathrm{~cm}^{-1}$ corresponding to $\mathrm{PEO},{ }^{30}$ the intensity of the peak at $1108 \mathrm{~cm}^{-1}$ corresponding to PCL was measured and a standard deviation of 0.26 was calculated (Fig. S3a, ESI $\dagger$ ). This traduces the inhomogeneity of the sample induced by the macrophase separation between the two immiscible PEO and PCL polymers. At high temperature, very few Diels-Alder adducts are formed and thus only a few couplings between PEO and PCL occurs limiting the mixture compatibilization. In contrast, when a temperature of $90{ }^{\circ} \mathrm{C}$ is selected for the extrusion, the resulting blend collected after $45 \mathrm{~min}$ is more homogeneous. This is evidenced by the reduced variation of the Raman spectra measured on 15 different spot areas (Fig. S3b, $\left.\mathrm{ESI}^{\dagger}\right)$. In this case, the standard deviation is only 0.11 . To complete the Diels-Alder adducts formation, this homogeneous blend is then cured at $65{ }^{\circ} \mathrm{C}$, under 75 bars, for various times then shaped as a sheet with a thickness about $0.5 \mathrm{~mm}$. Swelling tests in chloroform evidenced the network formation with an insoluble fraction of $60 \%$ obtained after $1 \mathrm{~h}$ of curing (Table 1). The crosslinking is improved by increasing the curing time. It is nearly complete for $72 \mathrm{~h}$ at $65{ }^{\circ} \mathrm{C}$ as evidenced by the very high insoluble fraction (96\%) and the decrease of the swelling ratio down to $1000 \%$ for the $51: 49$ composition (Table 1). This is also confirmed by the disappearance of the characteristic peaks of the furan at $1503 \mathrm{~cm}^{-1}(\mathrm{C}=\mathrm{C}$ stretching $)$ and maleimide at $1587 \mathrm{~cm}^{-1}(\mathrm{C}=\mathrm{C}$ stretching $)$ and at $1770 \mathrm{~cm}^{-1}(\mathrm{C}=\mathrm{O}$ stretching) moieties on the Raman spectrum recorded on the PEO-PCL mixture after $72 \mathrm{~h}$ of curing (Fig. S4, $\mathrm{ESI} \dagger)$.

When the same process is applied to the 70:30 PEO/PCL mixture, the insoluble fraction remains high (Table 1). The swelling ratio in chloroform increases but it is partially caused by the higher PEO content that swells more than PCL in this solvent. It is remarkable to observe that for both compositions, a high insoluble fraction is observed at the end of the postcuring process, which traduces the efficient coupling between furane and maleimide moieties whereas these are capping the chain-ends of the two immiscible PEO and PCL stars. The peculiar multi-arm architecture of the selected precursors which favours the network formation combined with the welladjusted extrusion temperature to allow enough Diels-Alder adducts formation and thus enough coupling between PEO and PCL stars is most probably responsible for the success in reaching the covalent networks in so high yields. These yields 
Table 1 Swelling experiments in chloroform and water for several PEO4FUR/PCL-4MAL blend compositions measured after melt-blending at $90{ }^{\circ} \mathrm{C}$ for $45 \mathrm{~min}$ followed by a post-curing treatment

\begin{tabular}{|c|c|c|c|c|c|}
\hline $\begin{array}{l}\text { Composition } \\
\text { PEO : PCL }\end{array}$ & $\begin{array}{l}\text { Curing } \\
\text { time at } \\
65^{\circ} \mathrm{C}(\mathrm{h})\end{array}$ & $\begin{array}{l}\text { Insoluble } \\
\text { fraction } \\
\text { in } \mathrm{CHCl}_{3} \\
(\%)\end{array}$ & $\begin{array}{l}\text { Swelling } \\
\text { ratio in } \\
\mathrm{CHCl}_{3}(\%)\end{array}$ & $\begin{array}{l}\text { Insoluble } \\
\text { fraction } \\
\text { in water } \\
(\%)\end{array}$ & $\begin{array}{l}\text { Swelling } \\
\text { ratio } \\
\text { in water } \\
(\%)\end{array}$ \\
\hline $51: 49$ & 1 & 60 & 2500 & n.d. & n.d. \\
\hline $51: 49$ & 72 & 96 & 1000 & 100 & 90 \\
\hline $70: 30$ & 72 & 86 & 1900 & 95 & 206 \\
\hline $70: 30$ & $\operatorname{Recycling}^{a}$ & 76 & 2600 & 82 & 260 \\
\hline $51: 49$ & Recycling $^{b}$ & 81 & 1250 & 100 & 103 \\
\hline $70: 30$ & $\mathrm{PBS}^{\mathrm{C}}$ & 86 & 1950 & 94 & 184 \\
\hline $51: 49$ & $\mathrm{PBS}^{c}$ & 91 & 1500 & 100 & 90 \\
\hline
\end{tabular}

${ }^{a}$ Recycled material (method A). ${ }^{b}$ Recycled material (method B). ${ }^{c}$ Sample after 1-month immersion in PBS buffer.

are indeed fully comparable to those observed for other reported covalent networks, i.e. PCL/PEO IPNs crosslinked by the polymerization of acrylic chain-ends for which the insoluble fraction varies from 87 to $91 \% .{ }^{23}$ In the present case, the crossreactivity between both PCL and PEO partners that are not reacting with themselves in contrast to acrylic systems, also favours the rapid compatibilization and thus the intimate blending of both partners accounting for the observed very high insoluble fraction.

1.2 Water swelling of the networks. In these hybrid covalent networks, the PEO component was selected to bring the hydrophilicity necessary to impart the foreseen water triggered shape-memory effect. The swelling behaviour in water was thus investigated for these hybrid CAN of both compositions. They exhibit a significant water uptake that expectedly increases with the PEO content (Table 1). The swelling ratio reaches $90 \%$ for the 51:49 sample. Considering that only the PEO phase is swelling in water, this swelling ratio measured for the 51:49 PEO:PCL stars-based network exhibiting PEO segment length between crosslinks of $2500 \mathrm{~g} \mathrm{~mol}^{-1}$ logically falls in between previously described 50:50 PCL: PEO systems that report a water

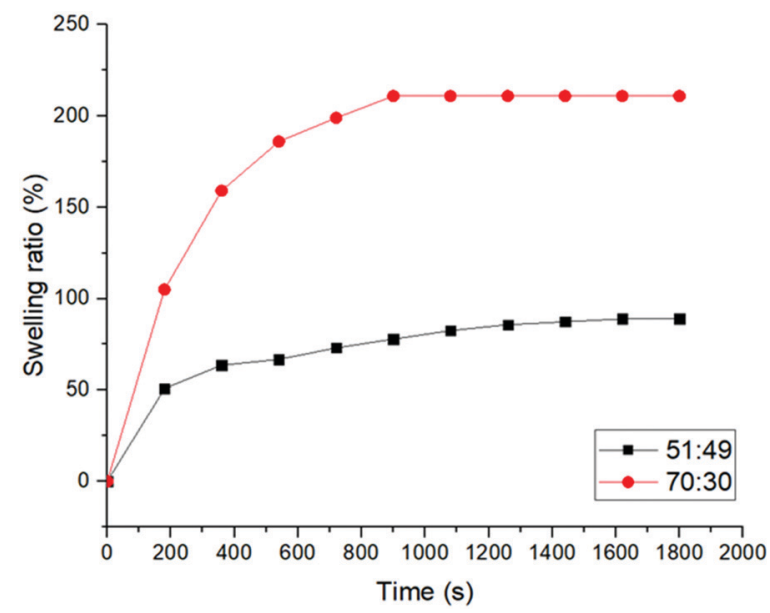

Fig. 1 Swelling kinetics in water of the hybrid networks of both compositions. swelling of $50 \%$ for covalent IPN with PEO length $2000 \mathrm{~g} \mathrm{~mol}^{-123}$ and $120 \%$ for TPU with PEO length $10000 \mathrm{~g} \mathrm{~mol}^{-1} \cdot{ }^{21}$ It is worth mentioning that in this selective solvent for PEO, the insoluble fraction is very high for both sample compositions which confirms the efficiency of the multi-arm PEO stars to covalently bind to the PCL ones leading to a stable network. The rate of water swelling of these hybrid CANs was also investigated (Fig. 1). The equilibrium is reached after $15 \mathrm{~min}$ for the most hydrophilic network (70:30) and $30 \mathrm{~min}$ for the $51: 49$ for samples with a thickness of $0.5 \mathrm{~mm}$. Knowing that the swelling rate is limited by the water diffusion in the sample and is thus thickness dependent, these data are quite comparable to the reported PCL:PEO TPU of lower thickness and crosslinking density $(8 \mathrm{~min}$ for a thickness of $350 \mu \mathrm{m}$, PEO:PCL 50:50, PEO10k, 120\% of swelling). ${ }^{21}$ It is remarkable to observe that in the studied covalent hybrid networks, especially in the 51:49 (lowest PEO content), the PEO phase made of PEO segments of $2.5 \mathrm{k}$ (4-arm stars of 10k), is well accessible to water which quickly penetrates the network and swells it efficiently which traduces the intimate homogeneity of PEO and PCL stars in the hybrid CAN resulting from the use of cross-reactive stars.

1.3 Thermal properties of the networks. The thermal properties of the PEO-PCL hybrid networks were analysed by DSC. Note that all the starting stars are semi-crystalline materials exhibiting a $T_{\mathrm{m}}$ around $60{ }^{\circ} \mathrm{C}$ and a crystallinity degree of $76 \%$ for PEO4-FUR-10k and $60 \%$ for PCL4-MAL-8k, respectively. The DSC traces of the hybrid networks were recorded for both compositions (Fig. 2 and Fig. S5, ESI $\dagger$ ).

They show one well-defined melting peak around $40{ }^{\circ} \mathrm{C}$ evidencing the remaining ability of the material to crystallize even after crosslinking. These results are in contrast to reported PCL:PEO IPN obtained by polymerization of acrylic end-capped

a)

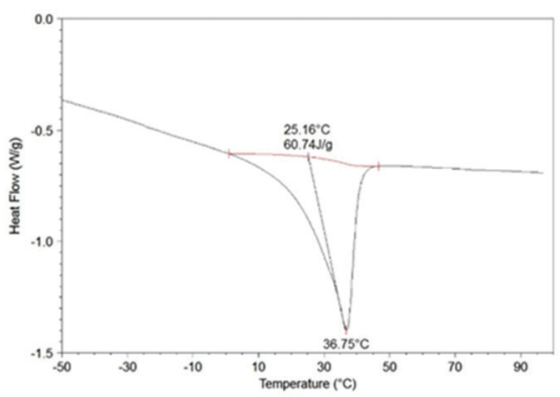

b)

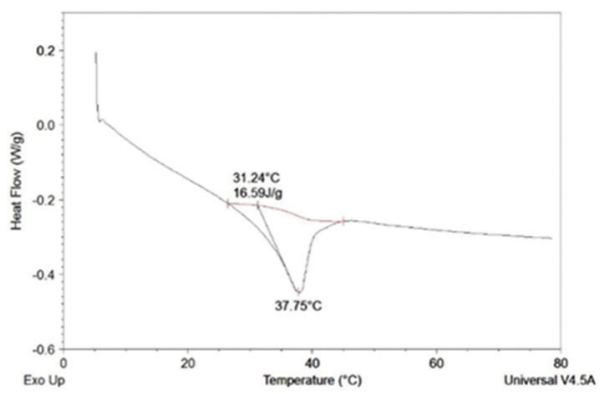

Fig. 2 DSC traces for the 51:49 network in the dry state (a) and hydrated state (b). 
PCL and PEO chains for which the PEO crystallization is prevented for networks with short PEO segments $\left(2000 \mathrm{~g} \mathrm{~mol}^{-1}\right) \cdot^{22,23}$ The 4-arm star-shaped architecture of both PCL and PEO phases is most probably at the origin of the preservation of crystallinity of both phases in the present case. Indeed, if the PEO segment length is also short $\left(2500 \mathrm{~g} \mathrm{~mol}^{-1}\right)$, four segments are connected at the same junction due to the star architecture which enriches locally the PEO phase allowing its crystallization.

To estimate the degree of crystallinity of the hybrid networks, we considered the proportion of both polymers in the network and take the average value. The melting enthalpy of a $100 \%$ crystalline PEO and PCL being $214 \mathrm{~J} \mathrm{~g}^{-1}$ and $140 \mathrm{~J} \mathrm{~g}^{-1}$ respectively, the crystallinity degree was estimated around $30-35 \%$ for both networks. As expected, the crystallinity decreases after crosslinking but remains quite significant. For the sake of comparison, a network formed by Diels-Alder addition between PCL-4FUR8k and PCL-4MAL8k exhibit a $T_{\mathrm{m}}$ at $44.4{ }^{\circ} \mathrm{C}$ and a crystallinity degree of $37 \%,{ }^{6}$ thus a quite similar reduction of the crystallinity degree and the melting temperature as compared to the stars before cross-linking. These PCL networks show temperature triggered shape-memory with excellent fixity and recovery. Therefore, such SM performances can be foreseen for the PEO:PCL hybrid networks. Interestingly, a DSC curve was recorded on the hydrated 51:49 network (Fig. 2b). Only the PEO phase is expected to be swollen while the hydrophobic PCL should remain crystallized. Indeed, a crystallization peak is clearly observed around $40{ }^{\circ} \mathrm{C}$ with a crystallinity degree of $12 \%$, i.e. slightly less than the half of the dry sample. This confirms the complete swelling of the PEO phase and clearly evidences the ability of the PCL phase to keep its crystallinity after complete swelling of the hybrid network in water.

1.4 Mechanical properties of the networks. The mechanical robustness of the hybrid CANs was determined by tensile testing. The Young modulus, stress and elongation at break are reported for both networks compositions in Table 2. As already observed in case of polyacrylate PEO/PCL IPN, ${ }^{23}$ the Young modulus and stress at break increase when the PEO content increases. The elongation at break (above 300\% for the hybrid CANs) is higher than the reported one for IPN which levels at $200-250 \% .^{23}$ In the hydrated state, a higher. Nevertheless, the stress-strain curves (Fig. S6, ESI $\dagger$ ) profile show a plateau after 50\% elongation which can be attributed to stress-induced network debonding due to the mechanically triggered retro-Diels-Alder reaction. ${ }^{31}$ As compared to non-covalent TPU systems for which yield point is reached around $25 \%$ elongation, ${ }^{21}$ the elastic deformation is

Table 2 Mechanical properties of networks of different compositions measured at room temperature in the dry and the hydrated state

\begin{tabular}{lllcr}
\hline Composition PEO:PCL & Hydration state & $E(\mathrm{MPa})$ & $\sigma(\mathrm{MPa})$ & $\varepsilon(\%)$ \\
\hline $51: 49$ & Dry & 31 & 6.2 & 600 \\
$51: 49$ & Hydrated & 3.1 & 1.9 & 150 \\
$70: 30$ & Dry & 75 & 11.2 & 428 \\
$70: 30$ & Hydrated & 1.3 & 0.3 & 50
\end{tabular}

$E$ : Young modulus, $\sigma$ : stress at break, $\varepsilon$ : elongation at break. thus two times higher for these CANs that appear thus well adapted for shape-memory experiments.

Mechanical properties are obviously impacted by the water swelling. The stress-strain curves show a fully elastic profile, the plateau observed in the dry state disappearing (Fig. S6, ESI $\dagger$ ). The hydration of the PEO segments increases their mobility and soften the samples so that the Young modulus is divided by 10 for the 51:49 network (Table 2 and Fig. S6, ESI $\dagger$ ) which is in line with reported TPU systems. ${ }^{21}$ The stress and elongation at break are also lower for hydrated samples as compared to dry ones. Nevertheless, even when the material is fully hydrated, it owns sufficient mechanical properties to be handled with an elongation at break still around 150\% and stress at break of 1.9 MPa for the 51:49 network. The Young modulus also remains higher as compared to SM networks based on PEO and PTHF developed for medical device. ${ }^{32}$ Watersensitive shape-memory can thus be foreseen for networks of both compositions.

\section{Shape-memory properties of the networks}

2.1 Temperature-triggered SM of dry networks. As evidenced by DSC analysis, the hybrid CANs are semi-crystalline and should therefore exhibit temperature triggered shape-memory properties. The quantitative measurement of the fixity and recovery was performed by dynamic mechanical analysis (DMA) for 4 successive shape-memory cycles in the dry state (Fig. 3a). The data collected from Fig. 3a are gathered in Table S1 (ESI $\dagger$ ) for the PEO/PCL 51:49 network. Very high fixity (98\%) and recovery (97\%) are obtained for each cycle except for the first training cycle $^{33}$ for which a recovery of $85 \%$ is reached. These results are as good as CANs entirely made of PCL (i.e. resulting of coupling PCL-4FUR and PCL-4MAL) ${ }^{6}$ and as PEO/PCL IPN. ${ }^{22,23}$

Interestingly, only a limited creep effect is observed from cycle to cycle for this PEO-PCL hybrid network as compared to similar furan/maleimide CANs composed of $100 \%$ PCL. $^{6}$ This creep phenomenon is caused by the occurrence of some stress-induced retro-Diels-Alder reactions at $65{ }^{\circ} \mathrm{C}$ leading to the entropic relaxation of the disconnected polymer chains. This phenomenon is less pronounced for the PEO-PCL hybrid network most probably because of the lower elongation reached here, i.e. $\sim 90 \%$, as compared to $\sim 150 \%$ for the pure PCL network.

Fig. 3b illustrates the temperature-triggered SM of the $70: 30$ PEO/PCL hybrid network. This more rigid sample because of the high PEO content can be elastically deformed between $50{ }^{\circ} \mathrm{C}$ and $70{ }^{\circ} \mathrm{C}$ and keeps well the temporary shape after cooling to room temperature and stress release (high $R_{\mathrm{f}}$, Table 3 ). By heating again to $65{ }^{\circ} \mathrm{C}$, the material recovers its initial shape in a few seconds with excellent fidelity (high $R_{\mathrm{r}}$, Table 3 ).

2.2 Water-triggered SM at room temperature. The watertriggered shape-memory was tested by immersing $0.5 \mathrm{~mm}$ thick samples in water in order to swell the PEO segments of the network and provide them mobility. After equilibration during $60 \mathrm{~min}$ at room temperature in water, the swollen material has doubled its volume and can be easily deformed, e.g. as a ring. It keeps the given temporary shape after sequential drying at 
a)

b)
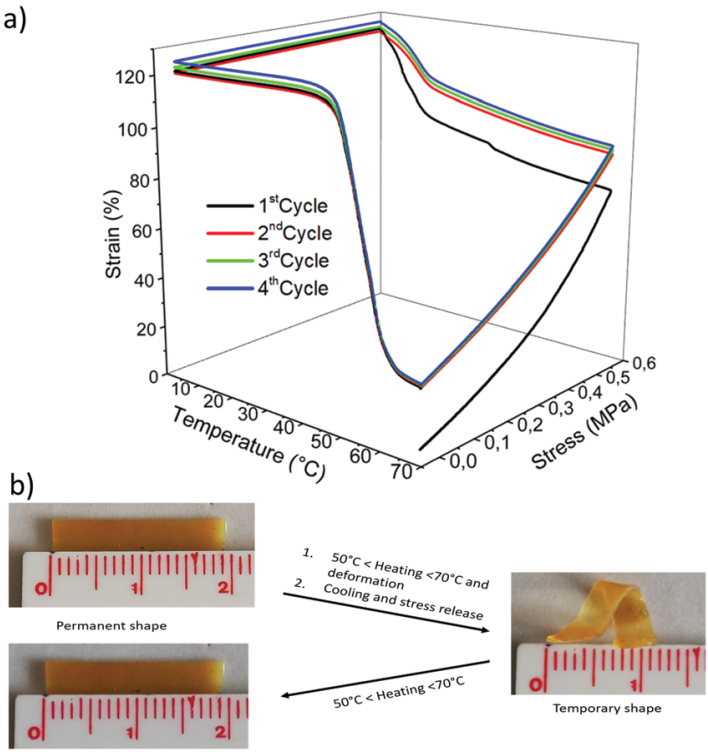

Fig. 3 Programming and temperature triggered shape-memory in the dry state: (a) 4 cycles recorded by DMA (stress ramp: $0.06 \mathrm{MPa} \mathrm{min}{ }^{-1}$; temperature ramp: $3{ }^{\circ} \mathrm{C} \min ^{-1}$ on heating and cooling) for the $51: 49$ network (b) images illustrating 1 cycle for the $70: 30$ network.

room temperature and stress release (Fig. 4). As evidenced from the measurement of the distance between ring edges on the dried ring (temporary shape) before and after stress release, a fixity close to $100 \%$ is obtained for CANs of both compositions. Then, immersing again the dry samples in water triggers the hydrated-shape recovery. As illustrated in Fig. 4, the shape recovery is not complete even after reaching the swelling equilibrium, i.e. $45 \mathrm{~min}$ immersion for the 51:49 and $20 \mathrm{~min}$ for the $70: 30$. Nevertheless, a recovery above $80 \%$ is measured for the most hydrophilic $70: 30$ sample and about $75 \%$ for the 51:49 network (Table 3) that is comparable or higher than reported data for other water triggered PEO/PCL systems. ${ }^{21,34,35}$ The crystallization of amorphous PCL segments that are oriented by the applied stress during room temperature drying of the sample to fix the temporary shape is responsible of the observed incomplete shape recovery, these PCL crystallites being stable towards rehydration.

2.3 Water-triggered shape transition of a thermally-fixed temporary shape. Having demonstrated the efficient temperatureand water-triggered shape-memory properties of the hybrid networks, the investigation of a first combination of these properties, i.e. the water-triggered relaxation of a thermally

Table 3 Fixity and recovery ratios for the temperature and water triggered shape-memory of both networks compositions, before and after recycling

\begin{tabular}{llllll}
\hline \multicolumn{1}{l}{ Trigger } & \multicolumn{3}{l}{ Temperature } & & Water \\
\cline { 2 - 3 } \cline { 5 - 6 } Samples & $R_{\mathrm{f}}(\%)$ & $R_{\mathrm{r}}(\%)$ & & $R_{\mathrm{f}}(\%)$ & $R_{\mathrm{r}}(\%)$ \\
\hline $51: 49$ & $\approx 100$ & $\approx 100$ & & $\approx 100$ & $\approx 75$ \\
$51: 49$ recycled & $\approx 100$ & $\approx 100$ & & $\approx 100$ & $\approx 75$ \\
$70: 30$ & $\approx 100$ & $\approx 100$ & & $\approx 100$ & $\approx 80$ \\
$70: 30$ recycled & $\approx 100$ & $\approx 100$ & & $\approx 100$ & $\approx 75$
\end{tabular}

fixed temporary shape was considered. Storing a complex temporary shape by the thermal process is quite easy and quick because it does not require to evaporate the water at room temperature. In that process, both components, PCL and PEO are taking part to the temporary shape fixity thanks to their crystallization. Besides, it is an advantage for some applications, notably in vivo applications, to trigger a shape modification without heating above the body temperature but simply by hydration. At a temperature remaining below $50{ }^{\circ} \mathrm{C}($ e.g. at the body temperature), the hydration of the PEO segments allows the partial release of the stored stress and the softening of the material, leading to a final shape (shape used in the final application) intermediate between the temporary and the permanent shape.

This process is illustrated for both materials compositions in Fig. 5. The sample in the permanent shape is first heated at $65{ }^{\circ} \mathrm{C}$ to melt all the crystallites before being deformed in the temporary shape by applying a stress, cooling at room temperature and releasing the stress. Finally, the sample is placed into a water bath at room temperature, so that the only PEO phase will swell and release the stress while the hydrophobic PCL is preserving the stored deformation. After complete hydration (30 min or $20 \mathrm{~min}$ ) and a drying step of $24 \mathrm{~h}$, the final shape, intermediate between the temporary and the permanent shape is obtained and remains stable during time as far as the temperature is kept below $50{ }^{\circ} \mathrm{C}$. Noticeably, if the sample is heated again at $65{ }^{\circ} \mathrm{C}$ and dried, the initial permanent shape is fully recovered in a few seconds (not shown).

As expected, the relaxation of the temporary shape increases with the PEO content of the networks. As a consequence, a final shape close to the temporary shape will be obtained for samples with low PEO content (Fig. 5a) while a shape closer to the permanent shape will be reached for samples of high PEO content (Fig. 5b).

2.4 Memory of multiple shapes. Another remarkable feature of this type of materials is their capacity to memorize in a temporary shape, two different final shapes that can be recovered depending on the applied trigger, i.e. temperature or water. For that purpose, a two-step programming of the material is necessary as illustrated on Fig. S7 (ESI $\dagger$ ) (and on Fig. 7 for the recycled material). The starting CAN shape defined by the crosslinking reaction happening during the covalent network formation (called "permanent shape" until now) will constitute the first memorized shape (shape 1-dry state). In the first programming step, the shape of this sample is modified into the second memorized shape (shape 2-dry state) by classical temperature shape programming, i.e. heating at $65{ }^{\circ} \mathrm{C}$ to melt the material, deforming and cooling under stress followed by stress release. This shape 2 also exists in its hydrated version (shape 2-hydrated state) after immersion in water. As seen above, only a partial release of the deformation occurs during the hydration step, especially for networks with moderate PEO content. Finally, the temporary shape, different from both shapes 1 and 2 , is obtained by a second programming step, i.e. deforming at room temperature 

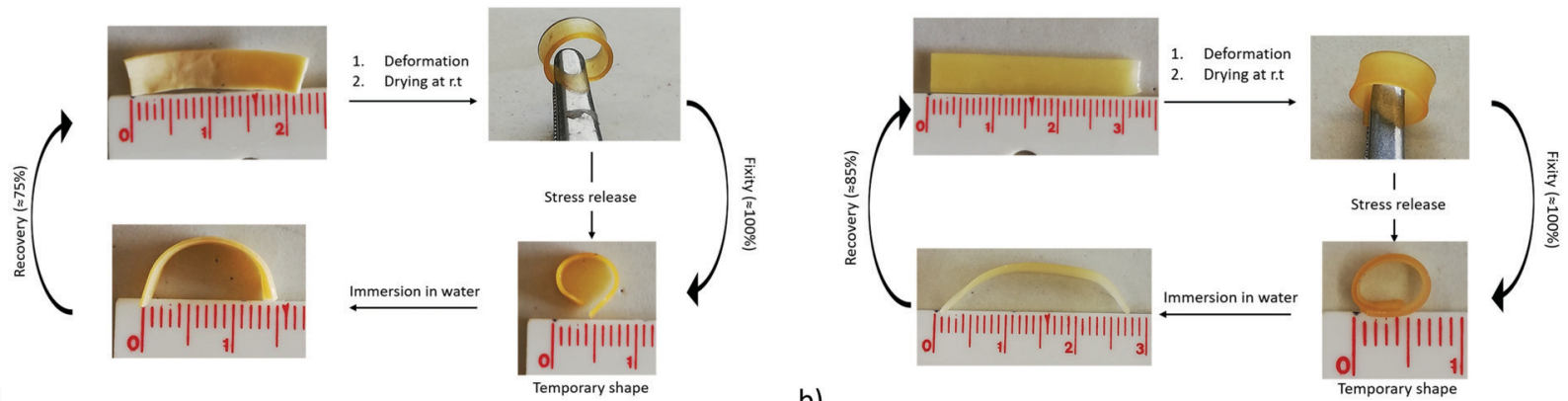

b)

Fig. 4 Water-triggered shape memory at room temperature of the PEO/PCL hybrid networks with a composition (a) $51: 49$ (b) $70: 30$.

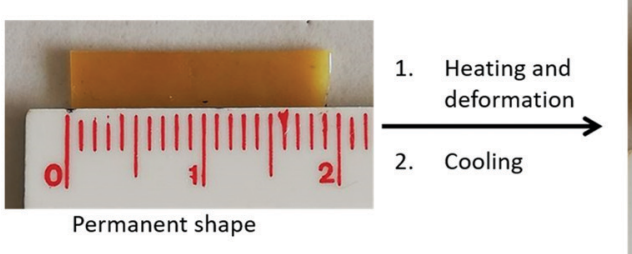

a)

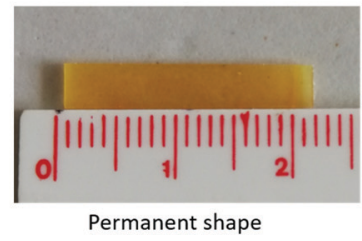

b)

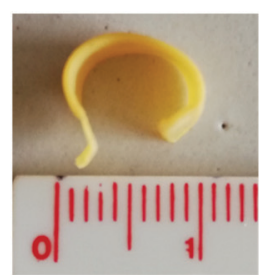

Final shape

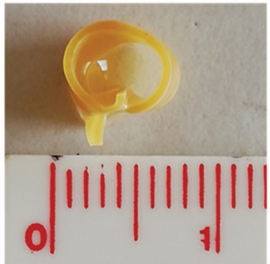

Temporary shape

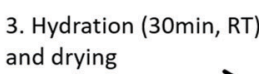
and drying

3. Hydration (20min, RT) and drying

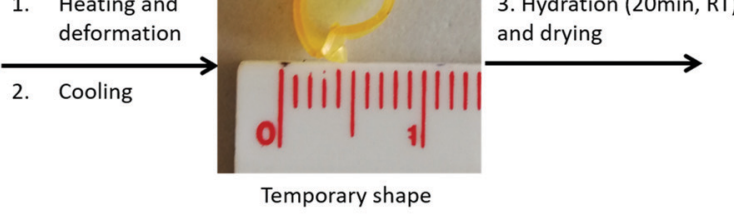

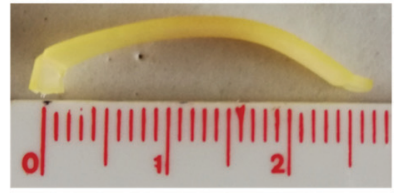

Final shape

Fig. 5 Illustration of the water-triggered shape transition of thermally stored temporary shape for the PEO/PCL hybrid networks with a composition (a) $51: 49$ (b) $70: 30$.

the water swollen shape 2 , followed by drying then release of the stress. This dry sample is going to keep stable its temporary shape as far as it is stored below $40{ }^{\circ} \mathrm{C}$ and in a dry atmosphere. When shape 1 has to be recovered, it can be simply heated a few seconds at $65{ }^{\circ} \mathrm{C}$ (Fig. S7, ESI $\dagger$ ). On the other hand, the recovery of shape 2 is triggered by immersion in water during $20 \mathrm{~min}$ keeping the temperature below $40{ }^{\circ} \mathrm{C}$. Interestingly, heating the sample in its shape 2 converts it in the hydrated shape 1 . This sequential recovery of shape 2 by sample hydration then shape 1 by further heating is especially interesting for surgery assisted by self-deploying medical devices.

\section{Reconfiguration of the permanent shape}

So far, the so-called permanent shape, i.e. the shape determined by the covalent crosslinking, was kept stable since heating processes were limited to $65{ }^{\circ} \mathrm{C}$. Nevertheless, thermo-cleavable furan-maleimide Diels-Alder adducts were purposely introduced to provide adaptable hybrid networks. Above $100{ }^{\circ} \mathrm{C}$, the cycloreversion, i.e. the retro Diels-Alder reaction significantly occurs. $^{27,28}$ Such CANs can advantageously be used for the reconfiguration of the permanent shape. As shown Fig. 6, the pristine flat film is pressed into a complex 3D mould heated at $100{ }^{\circ} \mathrm{C}$. This temperature is kept constant for $24 \mathrm{~h}$ to allow the retro Diels-Alder reaction to occur. After $24 \mathrm{~h}$, the temperature is reduced to $60{ }^{\circ} \mathrm{C}$ and kept constant for $72 \mathrm{~h}$ to form again the DA adducts and consequently restore the network in a novel permanent shape (Fig. 6). This 3Dreconfigured sample is now able to enter e.g. a temperature triggered SM cycle in which the memorized shape corresponds to the moulded 3D object as exemplified Fig. 6 (right part). Besides, the easy morphing of the material into more complex shapes is also demonstrated in Fig. S8 (ESI $\dagger$ ) by locally heating at $120{ }^{\circ} \mathrm{C}$ during folding ( 3 folds). Since the material does not conduct heat, the local control of the sample reconfiguration is successful allowing to origami design complex shapes. The good performances (high fixity and recovery) of the thermal shape memory of this locally reconfigured sample are also illustrated figure S8.

\section{Recycling of the networks}

Owing to the significant cyclo-reversibility of the furanmaleimide Diels-Alder adduct above $100{ }^{\circ} \mathrm{C},{ }^{27,28}$ it is possible 


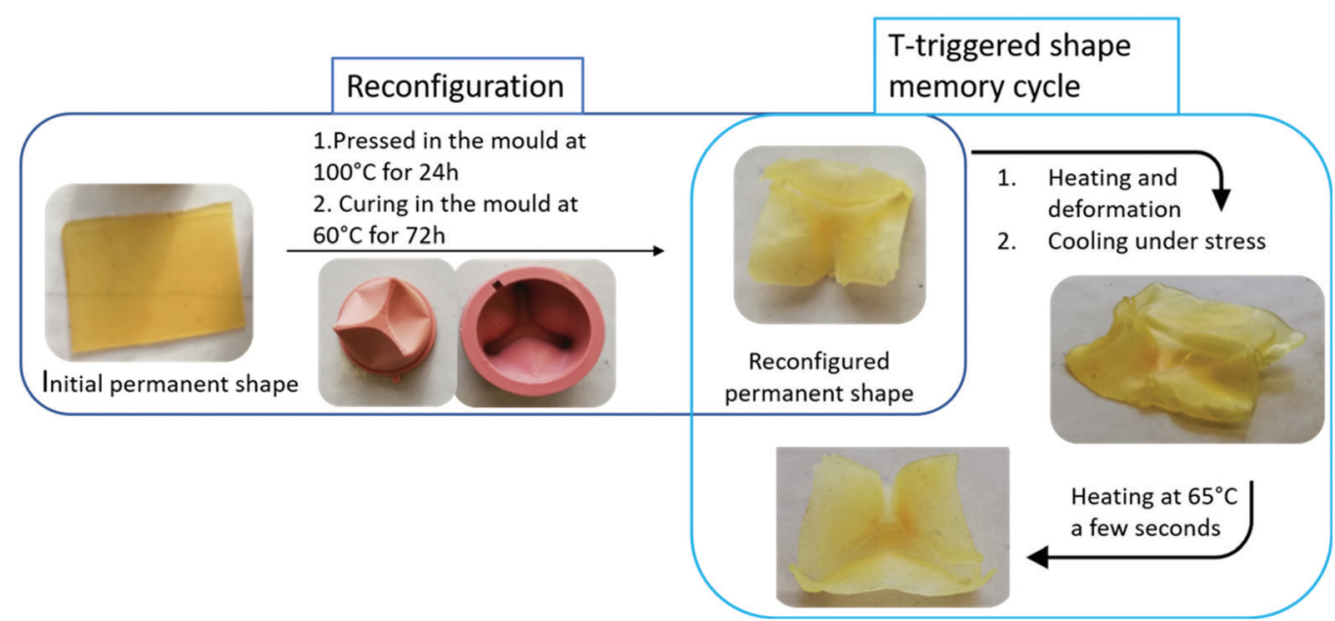

Fig. 6 Reconfiguration of the flat sheet CAN in a 3D object and temperature triggered shape-memory of this reconfigured sample made of the 70:30 CAN.

not only to reconfigure the permanent shape but also to recycle the material as shown Fig. S9 (ESI†). The recycled hybrid network is homogeneous and exhibits a slightly lower crosslinking density compared to the pristine material, as confirmed by swelling experiments in chloroform (Table 1-recycled). This mainly impacts the elongation at break that decreases after recycling (Fig. S6, ESI $\dagger$ ), while the Young modulus and stress at break remain similar. These observations confirm that the reversibility of the reaction efficiently occurs during the recycling of the material and that reprocessing is not limited by the immiscibility of the two star-polymers. The swelling in water is also very similar to the one of the material before recycling (Table 1) which is in line with the fully preserved water, thermoand multi-triggered SM properties (Fig. S9, ESI $\dagger$ and Fig. 7). Indeed, the fixity and the recovery of the water and heattriggered shape-memory materials are still the same than the pristine one (Table 3). The recycled material still crystalizes and the crystallinity degree is even slightly higher than before recycling (Fig. S10, ESI $\dagger$ ).

\section{Hydrolytic stability of the networks}

PCL being hydrolytically degradable and since PEO facilitates water penetration in the network, the stability of the samples in water at pH 7.4 was studied after one month. The integrity of the network is confirmed by swelling experiments in chloroform (Table 1). Only a moderate increase of the swelling ratio in chloroform is observed for the 51:49 sample indicating a limited number of bonds ruptures of the network. The insoluble fractions remain very high after one month of immersion in PBS. This very limited network degradation does not impact the temperature shape-memory properties that are well-preserved after one month as confirmed by DMA measurements (Fig. 8 and Table S2, ESI $\dagger$ ).

Nevertheless, a longer ageing in PBS starts to impact the elongation at break which decreases after 2 months immersion in PBS (Fig. S6, ESI $\dagger$ ). Even if the Young modulus is found unchanged (Table S3, ESI $\dagger$ ), it shows that these samples are preserved from hydrolytic degradation in neutral conditions for 1 month before showing alteration of mechanical properties.

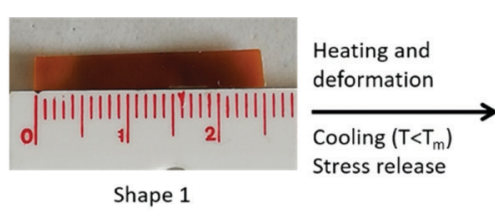

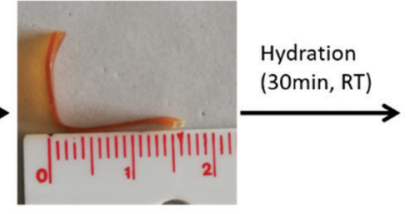

Shape 2 dry

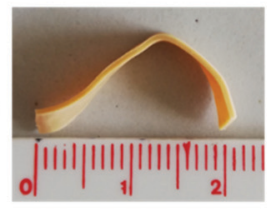

Shape 2 hydrated

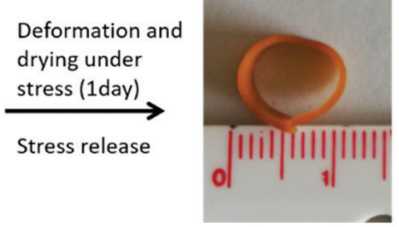

Temporary shape
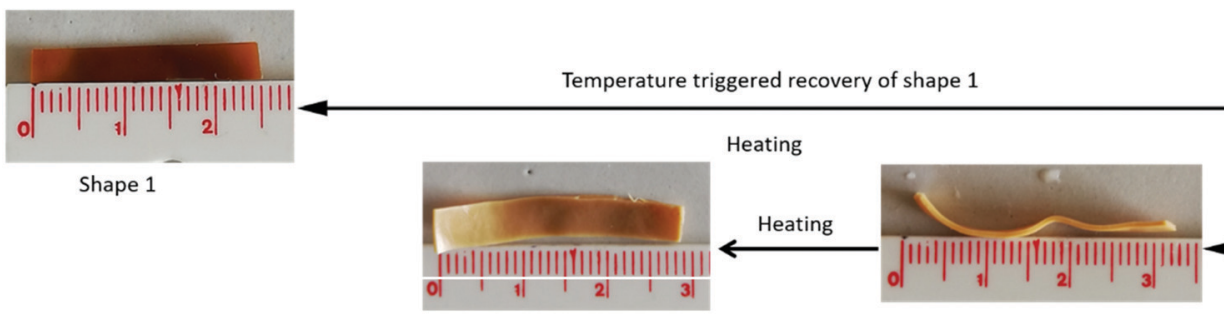

Shape 2 hydrated

Fig. 7 Multi stimulus shape-memory properties of the recycled $70: 30$ material. Temporary shape obtained by bending shape 2 at $\sim 270^{\circ}$. 


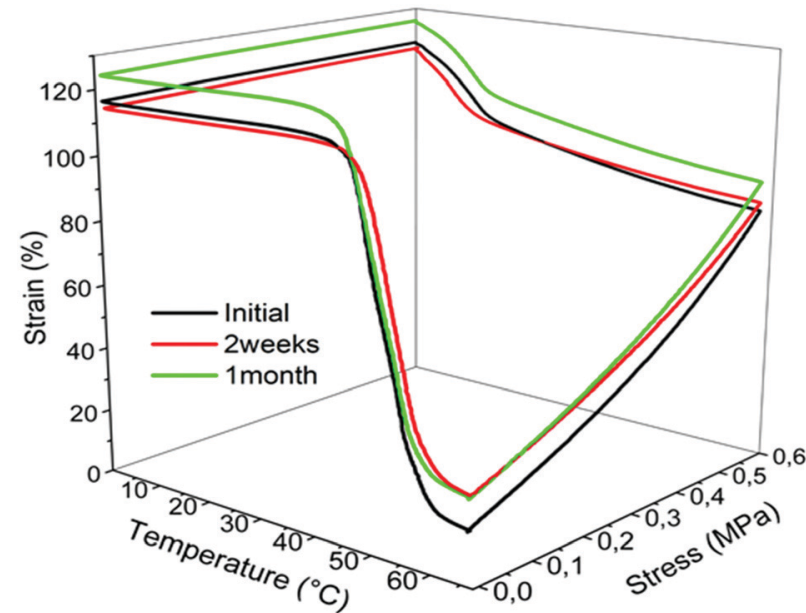

Fig. 8 DMA analysis in the dry state of the 51:49 before ageing in water (black curve), after two weeks (red curve) and one month (green curve) of immersion in PBS phosphate buffer.

\section{Conclusions}

Four-arm star-shaped PCL and PEO were successfully functionalized by maleimide and furan moieties, respectively. By optimizing the processing conditions, (i.e. temperature and time of extrusion, post annealing process, stoichiometry) hybrid networks have been obtained by chain-ends coupling via the formation of Diels-Alder adducts which are remarkably homogeneous knowing that these two polymers are immiscible. Playing on the molar mass of the PCL stars, networks of two different compositions (PEO/PCL 51:49 and 70:30) have been obtained. Even if the PEO and PCL stars are molecularly blended in the network owing to their cross-reactive coupling, both phases are still able to crystallize after crosslinking as demonstrated by DSC analysis of dry and water swollen materials. Therefore, both temperature and water triggered shape-memory properties are very efficient. Thanks to the covalent crosslinking, the elastic behaviour holds until a deformation of $50 \%$ which is twice the value reported for TPU systems. ${ }^{21}$

These results evidenced that thanks to the peculiar and welldefined structure of these CANs uniquely achieved by the blending of cross-reactive PEO and PCL homopolymers both having a 4-arm architecture, these hybrid networks exhibit crystallinity, mechanical robustness and water sensitivity. Consequently, advanced SM properties can be achieved so as memorizing two different shapes that are recovered by different triggers, namely temperature and water. The insertion of DielsAlder adducts in the network allowed for the first time to achieve recyclable and reconfigurable covalent PEO-PCL hybrid networks. In addition, no significant degradation of these hydrophilic polyester networks was observed after immersion during one month in PBS even for the most hydrophilic material containing $70 \%$ of PEO. These materials offer thus high opportunities for the development of biomedical applications especially in self-deployable devices for assisted complex surgeries. Mechanical properties in the hydrated state especially of the 51:49 sample are compatible for its use as self-deploying oesophageal stent for example. ${ }^{32}$ The efficient reconfiguration of flat sheets in more complex shapes by remolding opens the door to on-site shaping of medical device to precisely fit the patient needs answering the rapidly developing personalized medicine requirements.

\section{Conflicts of interest}

There are no conflicts to declare.

\section{Acknowledgements}

The authors thank the "Fonds Européen de Développement Régional (FEDER)" and Wallonia in the frame of the operational program "Wallonie-2020.EU" for funding the FEDER project "PROSTEM" and the DGO6 for supporting research in the frame of "SMARTDIF" project. The authors thank all the partners of the IN-Flow project carried out under the Interreg V-A Euregio Meuse-Rhine Program, with €2.1 million from the European Regional Development Funds (ERDF). By investing EU funds in Interreg projects, the European Union invests directly in economic development, innovation, territorial development, social inclusion, and education in the Euregio Meuse-Rhine.

\section{Notes and references}

1 A. Lendlein and O. E. C. Gould, Nat. Rev. Mater., 2019, 4, 116-133.

2 C. J. Kloxin, T. F. Scott, B. J. Adzima and C. N. Bowman, Macromolecules, 2010, 43, 2643-2653.

3 C. L. Lewis and E. M. Dell, J. Polym. Sci., Part B: Polym. Phys., 2016, 54, 1340-1364.

4 Y. Wu, Y. Wei and Y. Ji, Polym. Chem., 2020, 11, 5297-5320.

5 T. Defize, R. Riva, C. Jérôme and M. Alexandre, Macromol. Chem. Phys., 2012, 213, 187-197.

6 T. Defize, R. Riva, J. M. Raquez, P. Dubois, C. Jérôme and M. Alexandre, Macromol. Rapid Commun., 2011, 32, 1264-1269.

7 T. Defize, R. Riva, J. M. Thomassin, C. Jérôme and M. Alexandre, Macromol. Symp., 2011, 309-310, 154-161.

8 W. T. Oh, J. B. Lee, W. Choi, H. W. Bae, C. S. Kim, C. Y. Kim and H.-J. Sung, ACS Biomater. Sci. Eng., 2020, 6(7), 3784-3790.

9 Y. Zhou, D. Zhou, P. Cao, X. Zhang, Q. Wang, T. Wang, Z. Li, W. He, J. Ju and Y. Zhang, Macromol. Rapid Commun., 2021, 42, 2100176.

10 M. R. Pfau and M. Grunlan, J. Mater. Chem. B, 2021, 9, 4287-4297.

11 Q. Zhang, M. Wang, H. Ao, H. Luo, X. Deng and Y. Wan, Polym. Test., 2021, 96, 107086.

12 G. J. M. Antony, S. T. Aruna, C. S. Jarali and S. Raja, Polym. Bull., 2020, DOI: 10.1007/s00289-020-03427-6.

13 T. Hu, S. Xuan, Q. Shu, Z. Xu, L. Shen, J. Li and X. Gong, J. Mater. Chem. C, 2021, 9, 6568-6578. 
14 Y. Chen, X. Zhao, C. Luo, Y. Shao, M. B. Yang and B. Yin, Composites, Part A, 2020, 135, 105931.

15 N. Lorwanishpaisarn, P. Kasemsiri, K. Jetsrisuparb, J. T. N. Knijnenburg, S. Hiziroglu, U. Pongsa, P. Chindaprasirt and H. Uyama, Polym. Test., 2020, 81, 106159.

16 Y. Guo, Z. Lv, Y. Huo, L. Sun, S. Chen, Z. Liu, C. He, X. Bi, X. Fan and Z. You, J. Mater. Chem. B, 2019, 1, 123-132.

17 J. M. Korde and B. Kandasubramanian, Chem. Eng. J., 2020, 379, 122430.

18 M. Wu, P. Sukyai, D. Lv, F. Zhang, P. Wang, C. Liu and B. Li, Chem. Eng. J., 2020, 392, 123673.

19 W. Zhang, X. Leng, M. Gao, Z. Wei, Y. Wang and Y. Li, Polym. Test., 2021, 96, 107099.

20 X. Gu and P. T. Mather, Polymer, 2012, 53, 5924-5934.

21 X. Gu and P. T. Mather, RSC Adv., 2013, 3, 15783-15791.

22 Y. Feng, S. Zhang, L. Zhang, J. Guo and Y. Xu, Polym. Adv. Technol., 2011, 22, 2430-2438.

23 Y. Feng, H. Zhao, S. Zhang, L. Jiao, J. Lu, H. Wang and J. Guo, Macromol. Symp., 2011, 306-307, 18-26.

24 S. Buddhiranon, N. Kim and T. Kyu, Macromol. Chem. Phys., 2011, 212, 1379-1391.
25 Z. Qiu, T. Ikehara and T. Nishi, Polymer, 2003, 44, 3101-3106.

26 J. Li, Y. Zhang, Y. Jiacuo, Y. Shang, H. Huo and S. Jiang, Polym. Bull., 2012, 68, 1405-1423.

27 J. A. Syrett, G. Mantovani, W. R. S. Barton, D. Price and D. M. Haddleton, Polym. Chem., 2010, 1, 102-106.

28 A. Gandini, D. Coelho and A. J. D. Silvestre, Eur. Polym. J., 2008, 44, 4029-4036.

29 T. Defize, J. M. Thomassin, M. Alexandre, B. Gilbert, R. Riva and C. Jérôme, Polymer, 2016, 84, 234-242.

30 L. Koenig and A. C. Angood, J. Polym. Sci. Part A-2: Polym. Phys., 1970, 8(10), 1787-1796.

31 Z. Wang and S. L. Craig, Chem. Commun., 2019, 55, 12263-12266.

32 R. Liang, H. Yu, L. Wang, B. U. Amin, N. Wang, J. Fu, Y. Xing, D. Shen and Z. Ni, Chem. Mater., 2021, 33, 1190-1200.

33 I. A. Rousseau, Polym. Eng. Sci., 2008, 48, 2075-2089.

34 L. Sun and W. M. Huang, Mater. Des., 2010, 31, 2684-2689.

35 W. M. Huang, B. Yang, L. An, C. Li and Y. S. Chan, Appl. Phys. Lett., 2005, 86, 1-3. 